\title{
A difícil conciliação entre crescimento e sustentabilidade
}

\author{
Igor Zanoni Constant Carneiro Leão*
}

RESUMO - O conceito de sustentabilidade, se examinado em todas as suas consequências sociais e econômicas, envolve, na visão de seus maiores comentadores, uma mudança ética e valorativa, implicando uma verdadeira revolução na vida humana e apontando para novas utopias sociais.

Palavras-chave: Sustentabilidade. Ecologia. Socialismo.

Em um artigo famoso, Sobre o papel do trabalho na transformação do macaco em homem, Engels afirma que se o trabalho é a condição básica e fundamental de toda vida humana, isto é verdade a um tal ponto que o trabalho criou o próprio homem. Todavia, no capitalismo, ao produzirem e trocarem com o único fim de obter lucros imediatos, os industriais ou comerciantes só levam em conta os resultados mais próximos dando-se por satisfeitos por obter o lucro habitual, não lhes interessando o que possa ocorrer depois com essa mercadoria e seu comprador.

A partir daí Engels indica que o mesmo se dá com as consequências naturais dessas mesmas ações:

\footnotetext{
Quando, em Cuba, os plantadores espanhóis queimavam os bosques nas encostas das montanhas para obter com a cinza um adubo que só lhes permitia fertilizar uma geração de cafeeiros de alto rendimento, pouco lhes interessava que as chuvas torrenciais dos trópicos varressem a camada vegetal do solo, privada da proteção das árvores, e não deixassem depois de si senão rochas desnudas! (ENGELS, 1975).
}

Engels lembra outros exemplos de efeitos danosos sobre a natureza e a população desse tipo de ótica estritamente mercantil que, aliás, não é exclusiva do modo de produção capitalista.

As observações de Engels referem-se à difícil conciliação entre crescimento econômico e o que hoje chamamos de sustentabilidade ambiental, e como seres humanos são afetados por essa dificuldade. Alguns autores mais recentes chegaram a negar que ela pudesse ser superada. Assim, Nicholas Georgescu-Roegen, a partir de 1971, alertou para o fato de que as atividades econômicas transformam gradualmente energia em formas de calor inutilizáveis. A energia está sempre passando da condição de disponível para não disponível. O crescimento

\footnotetext{
${ }^{*}$ Doutor em Economia pela Universidade Estadual de Campinas. É professor do Departamento de Economia da Universidade Federal do Paraná. Endereço eletrônico: igorzaleao@yahoo.com.br.
} 
econômico moderno exigiu a extração da energia de baixa entropia do carvão e do petróleo e um dia há de explorar mais diretamente a energia solar. Todavia, para este autor a continuidade do desenvolvimento se dará, em algum ponto do futuro, com decréscimo do produto ${ }^{1}$.

Baseado nisso, Georgescu-Roegen formulou um programa mínimo com oito pontos do que deveria ser feito:

Primeiro: proibir totalmente a guerra e todos os instrumentos de guerra. Segundo: ajudar os países desenvolvidos a atingir o mais rápido possível uma existência digna de ser vivida, mesmo que sem luxos. Terceiro: diminuir progressivamente a população até um nível no qual uma agricultura orgânica bastasse à sua conveniente nutrição. Quarto: evitar todo e qualquer desperdício de energia enquanto se aguarda que a utilização da energia solar se torne viável ou que se consiga controlar os riscos da energia nuclear. Quinto: parar com o desejo de ter objetos completamente supérfluos e desnecessários, como os gadgets, fazendo assim com que cesse sua produção. Sexto: acabar com a moda - uma doença do espírito humano, segundo ele - fazendo os produtores só fabricarem bens duráveis. Sétimo: estimular o conserto das mercadorias duráveis, que seriam concebidas justamente para durar e não para serem descartadas tão rapidamente como acontece. Oitavo: reduzir o tempo de trabalho e redescobrir a importância do lazer para uma existência digna. (VEIGA; ZATZ, 2008).

Esta visão radical, claramente incompatível com a expansão dos mercados e sua transformação característica do capitalismo, foi retomada por Herman E. Daly, que propôs um desenvolvimento independente do crescimento. Na nossa época, essa alternativa parece inviável, mas pode ser a condição de sobrevivência do homem daqui a algum tempo. Vejamos algumas de suas ideias, seguindo José Eli da Veiga em Desenvolvimento sustentável: o desafio do século XXI.

Para Daly, só haveria uma alternativa à decadência ecológica dentro de uma "condição estacionária", na qual a economia continuaria a melhorar, em termos qualitativos, substituindo, por exemplo, energia fóssil por energia limpa, ao mesmo tempo em que seria abolida a mania do crescimento e do produto. Fica claro que a possível conciliação entre o crescimento econômico moderno e a conservação da natureza não é algo que possa ocorrer no curto prazo ou de forma isolada e específica. Por isso, o termo sustentável deve ser questionado e seu uso restringido.

A proposta de Daly é alcançar uma ideia já presente no século XIX em John Stuart Mill, chamada steady-state economy, ou uma "condição estacionária" do capital e da riqueza. Vejamos como Mill pensa a condição estacionária. Em primeiro lugar, ele advoga que o estado normal dos seres humanos não é o de sempre lutar para progredir do ponto de vista econômico. Ao invés disso, deve haver uma condição estacionária do capital com um novo ethos humano,

1 Veja-se José Eli da Veiga em Desenvolvimento sustentável: o desafio do século XXI, 2005. 
com aspirações mais elevadas e virtuosas. O melhor estado para a natureza humana é aquele em que, se por uma lado não há pobres, por outro ninguém pensa ser mais rico do que é, nem tem motivos para ser ultrapassado na luta pela vida.

O aumento da produção só deveria continuar a ser um objetivo importante nos países atrasados, e, nos mais avançados, bastaria uma melhor distribuição ao lado de uma limitação maior da população. Mill imagina que a melhor distribuição pode ser atingida por maior prudência dos indivíduos e por uma legislação favorável à maior equidade entre as fortunas. Esta sociedade seria preferível àquela que Stuart Mill via no mundo desenvolvido em meados do século XIX.

Ao mesmo tempo, Mill gostaria que fosse possível contemplar o mundo com espaço suficiente para atividade espontânea da natureza:

\begin{abstract}
Se a Terra tiver de perder a grande parte de amenidade que deve a coisas que o aumento ilimitado da riqueza da população extirpariam dela, simplesmente para possibilitar à Terra sustentar uma população maior, mas não uma população melhor ou mais feliz, espero sinceramente, por amor à posteridade, que a população se contente com permanecer estacionária, muito antes que a necessidade a obrigue a isto. (MILL², 1857, citado por VEIGA, 2010).
\end{abstract}

Nesta visão otimista de Mill as conquistas sobre as forças da natureza conseguidas pelo intelecto e pela energia de pesquisadores científicos se transformariam em propriedade comum da espécie humana, bem como meio para melhorar e elevar a sorte de todos. Entretanto, a condição estacionária seria uma situação sem crescimento da população e do estoque físico de capital, mas com contínua melhoria tecnológica e ética. Para Daly, esta seria a ideia mais relevante para pensar nas economias já maduras do Norte industrializado. A sustentabilidade precisa antes de tudo ser atingida nessa região, onde o nível de uso dos recursos é simultaneamente suficiente para permitir boa vida à população e compatível com a capacidade de suporte ambiental.

O crescimento da população e da produção não deve levar a humanidade a ultrapassar a capacidade de regeneração dos recursos e de absorção dos dejetos. No Norte avançado, a produção e a reprodução deveriam estar voltadas apenas à reposição. O crescimento físico deveria cessar com continuidade exclusiva de alterações qualitativas.

Para essa mudança radical de uma economia do crescimento para uma economia estável, mas não estática, Daly propõe quatro políticas inter-relacionadas. Em primeiro lugar, é preciso parar de contabilizar o consumo de capital natural como renda. A noção de sustentabilidade está inserida na própria definição de renda. O capital natural deixa de ser computado 2 MILL, S. Princípios de economia política: com algumas de suas aplicações à filosofia social, 1857. 
como um bem livre. Esta questão é bem reconhecida e estão sendo feitos esforços para buscar formas mais adequadas de contabilidade social.

A segunda política recomendada por Daly é tributar menos a renda e taxar mais o uso de recursos naturais. Isto significa remover os subsídios financeiros explícitos ao uso de energia, água, fertilizantes e até o desmatamento, bem como retirar os subsídios implícitos, ou seja, todos os custos externos para as comunidades gerados pela produção de mercadorias sobre as quais eles não incidem. É melhor economizar no uso da natureza devido aos altos custos externos de sua destruição e poluição, e ao mesmo tempo favorecer a ocupação de mão de obra capaz de reduzir o desemprego. É preciso usar ao máximo a substituição entre recursos naturais e trabalho.

A parte principal da receita pública deveria ser extraída de impostos sobre o uso da natureza, especialmente no que implica a sua destruição, o que exigiria uma reforma tributária ecológica crucial para o ajustamento estrutural. Essa reforma tributária ecológica deveria ser realizada gradualmente, começando pelas sociedades do Norte, o que indica claras dificuldades para as organizações internacionais que fazem o discurso do desenvolvimento sustentável.

A terceira política é maximizar a produtividade do capital natural no curto prazo e investir no crescimento de sua oferta no longo prazo. Essa ideia parece lógica e simples, mas requer uma substitutibilidade entre capital natural e capital construído, o que é uma hipótese irrealista. José Eli da Veiga dá exemplos simples, como o fato de a captura de peixes não ser limitada pelo número de embarcações cada vez mais eficientes, mas sim pelos cardumes que restam. A maior limitação parece ser a capacidade da atmosfera continuar a servir como depósito de dióxido de carbono, uma limitação maior do que os próprios estoques existentes de carvão e óleo.

Pode-se pensar em substituir capital natural por capital natural cultivado em florestas plantadas, criação de peixes e assim por diante, mas isso esbarra em serviços complementares essenciais do capital natural, como chuva, insolação, solo e outros. O capital natural cultivado também apresenta uma biodiversidade inferior ao dos recursos naturais propriamente ditos.

A quarta política indicada por Daly é assim exposta por José Eli da Veiga:

Sair da ideologia da integração econômica global do livre comércio, do livre movimento de capitais e do crescimento promovido por exportações em direção a uma orientação mais nacionalista que busque desenvolver a produção doméstica para mercados internos como primeira opção, recorrendo ao comércio internacional apenas quando claramente muito mais eficiente. (VEIGA, 2010). 
Para Daly, o globalismo não ajuda no sentido de um aumento de produtividade real dos recursos naturais, mas promove uma competição que rebaixa padrões salariais e exporta capital natural a baixos preços, enquanto os classifica como renda.

Daly, portanto, está longe de pensar a globalização como uma melhoria da condição humana contemporânea. Ele é um cético e a vê como uma ilusão dominada pelo entusiasmo, que deveria ser substituída pela primazia de interesses nacionais e de fatos culturais que dão sentido às identidades sócioterritoriais. A crescente importância de problemas mundiais pode ser vista exemplarmente no crescimento explosivo dos mercados financeiros e de suas consequências sobre a economia real.

Supondo a adoção pelo Norte desenvolvido das quatro políticas básicas propostas por Herman Daly e de outras necessárias para que se pudesse empreender uma passagem para um desenvolvimento sem crescimento, exigiria-se um profundo choque de altruísmo, ou "a change of heart, a renewal of the mind and a healthy dose of repentance", na fórmula do autor. Esta é uma visão religiosa criada por princípios éticos e morais hoje aceitos por muitos pensadores laicos, e poderia se tornar um exemplo histórico como poucos de mudanças radicais que surgiram de motivações extraeconômicas e foram influenciadas fortemente por valores e ideais.

Essa visão teria como desafio a solução de problemas globais e conflitos sociais sobre a sustentabilidade, como o desgaste da camada de ozônio, o aumento do efeito estufa e a perda de diversidade, entre outras questões relativas à dificuldade de preservar e expandir as liberdades substantivas de que as pessoas hoje desfrutam sem comprometer a capacidade das futuras gerações de desfrutarem uma liberdade semelhante ou maior.

Segundo Douglas E. Booth, admirador das ideias de Daly, o problema central aí está na força dos interesses que precisarão ser contrariados, especialmente nos países mais ricos. Para ele, seria preciso tentar vias de transição para um novo mundo que exigiria um incremento na consciência coletiva dos problemas ambientais. O movimento ambientalista deveria ter sucesso maior na luta por regulamentações dentro dos acordos internacionais, ao mesmo tempo em que a democracia econômica teria de se expandir numa perspectiva mais solidária e o consumo material deveria ser substituído por mais tempo livre e maior participação em atividades culturais.

Essas considerações são suficientes, a meu ver, para pensar no conceito de sustentabilidade como algo que vai muito além da preservação ambiental, atingindo a própria forma de reprodução da lógica social e econômica. Onde haveria força suficiente para inclinar a balança para longe da destruição dos recursos naturais, da biodiversidade, da poluição, do aquecimento global, da desertificação dos mares e ao mesmo tempo manter algo que se aproximasse do 
modo de produção capitalista?

Engels, no artigo citado anteriormente, pensava que um novo modo de produção conscientemente dirigido pelo conjunto dos valores sociais, essencialmente anulando a exploração dos homens e do ambiente, poderia induzir uma solução apontando para o que hoje chamamos sustentabilidade, um termo um pouco vago mas que vem sendo esclarecido por autores como Georgescu-Roegen e Herman Daly em toda sua radicalidade. Provavelmente, Engels estava longe de ter receitas para estes problemas cuja extensão ele não deve ter previsto. O fundamental, em minha opinião, é que enquanto o capitalismo se mantiver não como uma virtuosa "destruição criadora", na expressão de Schumpeter, mas como um forno que rapidamente corrói os fundamentos da vida e da cultura eticamente orientada, o socialismo e outras utopias, inclusive religiosas, terão seu lugar num debate mais do que urgente.

\section{REFERÊNCIAS}

ENGELS, F. Sobre o papel do trabalho na transformação do macaco em homem. In: MARX, K.; ENGELS, F. Textos. São Paulo: Edições Sociais, 1975.

VEIGA, J. E. da; ZATZ, L. Desenvolvimento sustentável, que bicho é esse? Campinas: Autores Associados, 2008.

VEIGA, J. E. da. Desenvolvimento sustentável: o desafio do século XXI. Rio de Janeiro: Garamond, 2010. 